\title{
Do Trainee Mindfulness Teachers Practice What They Teach? Motivation, Challenges, and Learning Gaps
}

\author{
Allison Bowden ${ }^{1} \cdot$ Katie Norton ${ }^{1}$ (D) $\cdot$ Gemma Maria Griffith ${ }^{1}$ (I)
}

Accepted: 21 November 2020 / Published online: 7 December 2020

(C) The Author(s) 2020

\begin{abstract}
Objectives Research concerned with mindfulness-based program (MBP) teacher training has focused on the importance of developing teacher competency and integrity, with little emphasis on the experience of trainees themselves. The aim of this study was to investigate the experiences of trainee MBPs teachers as they delivered their first MBPs, with a focus on how they utilized their personal mindfulness practice to support themselves during this time.

Methods We explored the experiences of university-based trainee teachers of Mindfulness-Based Stress Reduction (MBSR) when starting to teach, the ways they negotiated any challenges, and the extent to which they felt supported by their mindfulness practice. Semi-structured interviews were conducted with new MBSR teachers currently on a training course $(N=8)$. The interview data were analyzed using inductive thematic analysis.

Results The key findings of the study were that trainee teachers were deeply motivated to teach MBPs with great integrity; did not anticipate the amount of time and effort needed to deliver their first MBSR courses; had concerns about the viability of the 8week format of MBSR; needed more development in the area of self-reflection; and do indeed practice what they teach, and used their personal mindfulness practice to work with challenges.

Conclusions These findings show that trainee mindfulness teachers are actively engaged with developing their teaching skills, and offer directions for how the pedagogy of MBP teacher training may be further developed. Trainees might benefit from additional pedagogical input on the practicalities of delivering MBSR in community settings, and on the development of reflective skills.
\end{abstract}

Keywords Pedagogy $\cdot$ Mindfulness $\cdot$ Student $\cdot$ Qualitative $\cdot$ Well-being $\cdot$ Stress

Mindfulness-based programs (MBPs) have proliferated over the last 20 years, with MBPs introduced into various clinical and non-clinical settings, including education, healthcare, the workplace, and the criminal justice system (Crane et al. 2016; Mindfulness All-Party Parliamentary Group 2015). The two foundational MBPs, Mindfulness-Based Stress Reduction (MBSR) and Mindfulness-Based Cognitive Therapy (MBCT), are widely used in a variety of community and clinical settings, with much research focusing on participant outcomes (Chiesa and Seretti 2009; Khoury et al. 2013; Parsons et al. 2017). This demand for MBPs has, in turn, led to a

Gemma Maria Griffith

g.m.griffith@bangor.ac.uk

1 Centre for Mindfulness Research and Practice, School of Psychology, Bangor University, Brigantia Building, Penrhalt Road, Bangor LL57 2AS, UK demand for competent MBPs teachers who have undertaken rigorous training.

Mindfulness-based teaching has a vast pedagogy (Brandsma 2017: Crane 2009; McCown et al. 2011; Segal et al. 2013) and requires a strong skill set underpinned by theoretical knowledge. Trainee MBP teachers are required to gain knowledge and experience of their subject, develop resources, and evaluate their teaching, while also having knowledge of relational skills and underlying psychological and theoretical processes such as cognitive behavioral therapy (CBT) which underpin teaching for particular populations or in particular contexts (Crane 2014; Crane et al. 2016; Evans et al. 2015).

In addition to these requirements, teachers of MBPs are unique because their teaching must be rooted in their own personal mindfulness practice. Trainees are required to have a personal mindfulness practice for at least 12 months before enrolling on a teacher training course, and to continue this 
throughout teacher training. In essence, this allows teachers of MBPs to express through their teaching process an experiential, embodied knowing, rather than simply a conceptual knowledge of mindfulness (Crane et al. 2016; Griffith et al. 2019). The development of these skills takes time - many mindfulness teacher training courses are of 3 to 4-year duration and require assessment, and, like any professional training, may be stressful at times and impact the well-being of the trainee. This long training, however, seems to benefit participants; Rujgrok-Lupton et al. (2018) reported that higher teacher training levels were associated with more positive participant outcomes, although personal practice and teaching experience were not linked to participant outcomes.

Mindfulness-based teaching is emergent as a professional field, and the main driver of professionalism is the focus on the training and competence of teachers of MBPs and the qualities of fidelity and integrity they are required to demonstrate (British Association of Mindfulness-Based Approaches [BAMBA] 2019; Crane et al. 2010, 2012, 2016). Currently there are three universities in the UK, and others across the globe, which offer MBP teacher training at a post-graduate level, as well as a number of non-academic professional training organizations offering MBP teacher training (Crane et al. 2010). These are professional training courses that meet the demand for high-quality training programs, designed to produce competent teachers of MBPs (Evans et al. 2015). Bangor, Oxford, and Exeter universities developed a competency framework (the Mindfulness-Based Interventions Teaching Assessment Criteria [MBI-TAC], Crane et al. 2018), which outlined six domains of teaching competence such as curriculum adherence and embodiment of mindfulness. The MBI:TAC was designed to support teachers to uphold the highest standards of integrity and fidelity when delivering MBPs.

There are parallels between MBP training and other professional training programs such as counseling, psychology, and school teaching, in that these all involve trainees learning specific skills and working directly with others in a teaching/ supportive capacity. Generally, research indicates that there are a substantial number of trainees in these professions who report high levels of stress due to subject-specific concerns. For example, secondary school trainee teachers report that they find challenging pupil behavior stress inducing, and some counseling trainees hold unrealistic beliefs around their own ability to cope (Chaplain 2008; Truell 2001). A common theme, however, across those training in similar "support/caring" professions, was that many stressors among trainees were attributable to the training process itself, such as the degree to which trainees were prepared for likely challenges, lack of support systems, and a need for an explicit focus on the process of learning new skills (Chaplain 2008; Kumary and Baker 2008; Truell 2001). Valid, unexplored questions of MBP teacher training therefore are, does MBP teacher training lead to trainees experiencing similar stressors? Does the very process of MBP training evoke stressors, and, if so, could those stressors then be anticipated and mitigated by MBP training providers?

Teachers of MBPs are responsible for the integrity, quality, and standards of curricula delivery, and thus MBP teachers are regarded as the fulcrum point or conduit for the work (Crane 2016; Kabat-Zinn 2011). Kabat-Zinn wrote "The quality of MBSR as an intervention is only as good as the MBSR instructor and his or her understanding of what is required to deliver a truly mindfulness-based program" (2011, p.281). This understanding is thought to be demonstrated principally through the presence of the teacher, or the way in which the teacher embodies and models the qualities and attitudinal foundations of mindfulness (KabatZinn 2013). Crane et al. (2016) stated that the embodiment of attitudinal foundations (non-judgment, patience, beginner's mind, trust, non-striving, acceptance, and letting go) and qualities (including characteristics of compassion, warmth, kindness, and gentle curiosity) are essential ingredients of being a MBP teacher, together with competence, commitment to ongoing good practice, appropriate training, and personal practice and supervision. Mindfulness-based teacher training programs are designed with the key aims of supporting the trainee in the cultivation of an embodied understanding of self, of human vulnerability and resilience, a deep understanding of MBP curricula, and practical teaching skills. The curriculum design for trainees is thus intended to create capacity in teachers to convey mindfulness both implicitly (e.g., through embodiment or relational style) and explicitly through delivering curriculum content (Crane et al. 2010, 2016).

In addition, there are a number of practical skills needed when preparing to teach MBPs, including marketing, recruitment, and resource preparation. In order to deliver an MBP, teachers need skills in communication, networking, and partnering. Thus, teachers of MBPs can find themselves playing many roles (Bartley 2012). Given the level of personal and professional engagement involved in training to teach MBPs, and the wide-ranging skill set and commitment required, it is likely that teachers of MBPs may face considerable challenge and potential stress during their training process. Research has focused on the professional development of the MBP teacher and methods of establishing teacher competency and integrity (Crane and Reid 2016), while the direct experience of trainee MBP teachers has been relatively unexplored. A preliminary literature search was conducted in June 2020 through PsycINFO using the search terms: "mindfulness" "MBP," and "trainee teacher." The literature search revealed that no study had yet been published which focused on the experiences of trainee teachers in MBPs, although we did find one unpublished thesis about how mindfulness retreats are helpful to the development of MBP teachers (Girardini 2019). Research in this area is necessary for several reasons; knowing more about the experience of trainees is important in itself and 
may help to identify particular times of vulnerability to stressors during the training process and when teaching their first MBPs. It can also help training organizations refine and develop training curricula, and this in turn may be supportive of the development of trainee MBPs teachers.

Crane (2014) has written about the personal tensions that can be experienced when teaching MBPs, and how teachers of MBPs might struggle with concerns about not being good enough to teach and experience crises of confidence, even suffering feelings of inadequacy, shame, anxiety, and feeling like a fraud. Evans et al. (2015) commented on the lack of confidence and feelings of insecurity experienced by many MBP teachers, and how the deeply challenging work of practicing and teaching mindfulness is impacted further by the requirement of MBPs teachers to support participants to turn towards, and be with, sometimes very challenging mental and physical states. Exposure to vulnerable participants presenting with a range of physical and psychological difficulties could add another layer of challenge for those beginning teaching MBPs, compounded by performance anxiety alongside the stress of completing a rigorous MBPs teacher training program. Mindfulness teacher training, therefore, may subject trainees to multiple stressors.

Some researchers have explored the impact of one-off MBPs for health professional trainees. Rimes and Wingrove (2011) reported lower levels of stress in clinical psychology trainees who were offered MBPs, while Speeth (1982) reported that mindfulness fostered protective qualities of self-acceptance, which in turn helped to sustain well-being among psychotherapist trainees. Given that a personal mindfulness practice is a prerequisite and ongoing requirement of MBP teacher training, it may be expected that a mindfulness practice may serve as a protective factor to stressors encountered in the MBPs training process.

Explorations about how trainee teachers of MBPs fare during their training, and how far they draw upon mindfulness to sustain and nourish their well-being during their first foray into teaching MBSR, are not explored as yet in the literature. It was anticipated that this study would lead to greater understanding about the particular stresses experienced by MBPs trainee teachers in the UK and how they manage these stressors. The aims of this study were: 1) to explore the experiences of trainee teachers when teaching their first MBSR courses, and 2) to explore whether a personal mindfulness practice supports trainees when navigating the challenges of teacher training and teaching their first MBSR courses.

\section{Method}

\section{Participants}

Eight participants were interviewed (see Table 1 for demographic details). Inclusion criteria were: 1) trainee teachers of MBPs studying on a UK university-based MBPs teacher training course, 2) they had taught (or co-taught) a minimum of one and a maximum of three mindfulnessbased courses (MBSR) to general public populations. This latter criterion was in place to exclude more experienced MBPs teachers who may have had a different experience of teacher training.

Participants were excluded if they were teaching in a National Health Service (NHS) or other clinical settings, or taught MBCT. Teachers delivering MBPs in a healthcare context are often financed through their organizations, and so the stresses and pressures they experience as new teachers are likely to be different. Additionally, those who start teaching MBCT at an early stage of teacher training often have a professional background in CBT and deliver MBCT in their workplace, and so may have a very different experience to those delivering MBSR in community settings. We wanted to keep the sample as homogenous as possible (Braun and Clarke 2013) and therefore only recruited teacher-trainees working in community settings who taught MBSR.

\section{Procedure}

Ethical approval was gained from Bangor University. Gatekeepers from two UK universities which provide postgraduate mindfulness teacher training agreed to distribute recruitment materials directly to their students and on social media pages. Interested participants contacted the first author directly for more information about the study, and were sent the participant information sheet and consent form. If they returned a consent form and met the recruitment criteria, a mutually convenient time for a telephone interview was then arranged via email.

The telephone interviews lasted for up to an hour. The first author began the interview by collecting demographic data on participants (including age, gender, stage of training and number of years practicing mindfulness). The semi-structured interview guide consisted of eight questions and sub-questions and participants were free to reply in their own words. The interview guide drew from the first author's observations of other trainee MBPs teachers' priorities and concerns, as well as aiming to include a range of perspectives which integrated different experiential aspects of stress (Hanley 2002). The guide was then constructed and refined in accordance with recommendations on good qualitative interviewing techniques (Braun and Clarke 2013). Examples of questions were: What motivated you to want to become a teacher of mindfulness-based programs?; Is there anything you have found particularly challenging, or stressful about starting to teach? The methodology utilized in this study (thematic analysis) has been criticized for limiting participants' free association to the topic under investigation due to the structure and content which is inevitably imposed onto participants thinking 
Table 1 Participant demographic data

\begin{tabular}{|c|c|c|c|c|c|}
\hline Name & Gender & Age & Training & $\begin{array}{l}\text { No. of MBSR } \\
\text { courses taught }\end{array}$ & $\begin{array}{l}\text { Years of mindfulness } \\
\text { practice }\end{array}$ \\
\hline Fiona & Female & 48 & Year 2 & 3 & 10 \\
\hline Abi & Female & 50 & Year 2 & 2 & 4 \\
\hline Kim & Female & 53 & Year 2 & 3 & 6 \\
\hline Chris & Male & 40 & Year 2 & 1 & 10 \\
\hline David & Male & 52 & Year 2 & 1 & 9 \\
\hline Mel & Female & 42 & Year 1 & 1 & 5 \\
\hline Stephanie & Female & 56 & Year 1 & 3 & 5 \\
\hline Jo & Female & 63 & Year 2 & 2 & 5 \\
\hline
\end{tabular}

through the use of an interview agenda (Joffe 2012). To address this issue, the first author used the interview guide as a framework and the conversation followed the lead of the participant as far as possible, with the intentions of maximizing the richness of the data, and of adhering to the approach of inductive analysis, in which there is no predetermination about which aspects of the participant account the researcher is particularly interested (Willig 2013).

\section{Data Analysis}

The authors adhered to the American Psychological Association (APA) reporting standards for qualitative research in psychology (Levitt et al. 2018). Qualitative research is concerned with understanding and exploring the ways in which participants make meaning of their personal experience with a focus on participants' own terms of reference, rather than having these imposed by the researcher (Braun and Clarke 2013). Qualitative approaches were therefore considered to be suitable for the purposes of this study as they are appropriate for capturing the quality of participants' lived experience (Allen et al. 2009). Interviews were analyzed using inductive thematic analysis, which is a method that enables the identification of themes and patterns of meaning (or "meaning units," Willig 2013, p.61), from the data collected (Braun and Clarke 2006, 2013). While there are several varieties of thematic analysis, inductive thematic analysis was considered to be the most appropriate approach for this study as the analysis is grounded in the data, rather than the researcher's analytic preconceptions (Braun and Clarke 2006). This inductive approach was also chosen as this is a new area of study, and we wanted to foreground direct participant experience, rather than our interpretations of their experience. Data was collected via semistructured interviews that were then transcribed verbatim, with any identifying data (e.g., names, details about specific events, places or family members) anonymized during the write-up (Braun and Clarke 2013). All participants were given pseudonyms.

Inductive thematic analysis is a process of describing and quantifying phenomena as systematically and objectively as possible, by the categorization of themes that are identified from the data. Interview data was thus systematically analyzed using the six-stage phased method described by Braun and Clarke (2006). In keeping with good practice guidelines about conducting qualitative research, the intention was to identify themes that were distinctive and could stand alone, but also which fitted well together to form a coherent overall analysis (Braun and Clarke 2013; Levitt et al. 2018). Stage one involved the first author familiarizing herself with the data both through the transcription process and multiple readings of the interview transcripts. The second stage involved annotating the data and producing initial codes that aimed to identify the key themes most prevalent in the data. The coding process involved multiple readings of each transcript and highlighting "meaning units" (Willig 2013, p.61), ideas about which were notated in margins of the transcripts and which formed the basis of the coding frame. In the third stage, as patterns of themes began to cohere into overarching themes and subthemes, codes were collated to form a separate theme table for each interview transcript. Each theme table was scrutinized in order to ensure that the contents were relevant to answering the research questions. During the fourth stage, themes and sub-themes were then revised and refined, and this involved a "recursive" approach, that is going sideways, backwards and forwards across the entire data set, to ensure as far as possible that themes and sub-themes were distinct, relevant and coherent. During the fifth stage some sub-themes were excluded as they were not pertinent to the research question (e.g., interviewees' experiences of running monthly follow-up groups for their MBP 8-week course "graduates") and separate subthemes were collapsed with the intention of making the "story" of the data succinct. A detailed, written analysis of each theme was produced, leading to the production of the final report in the sixth stage, which aimed to validate the most salient points identified during the analysis and produce an account that was concise and compelling (Braun and Clarke 2006, 2013).

Yardley (2000) commented on the importance in qualitative research of transparency and the importance of openly reflecting on any factors that might have affected the analysis. 
The first author's interpretation of the analysis developed by applying a number of recommended checks intended to ensure, as far as possible, the consistency and plausibility of the account (Braun and Clarke 2013; Levitt et al. 2018). These included keeping a reflective journal, re-reading the interview transcripts after the initial draft of data themes and ensuring that the analysis and data matched each other. In addition, the second author worked closely alongside the first author throughout each stage of the process, checking the different stages of the analysis and the write-up of the identified themes.

\section{Results}

Using thematic analysis, the following superordinate themes were identified: motivation to teach; professional challenges; personal challenges; and practicing what they teach. The latter three superordinate themes contained nine subordinate themes between them (see Table 2).

\section{Superordinate Theme: Motivation to Teach}

The majority of participants articulated a strong motivation to teach MBPs to others, which were rooted in the benefits that they had personally gained from practicing mindfulness. Mel said:

[The MBSR course] genuinely like had such a huge impact on me, and it left me with [...] a real thirst $[. .$. for exploring and finding out more. And it, it touched me in a way that I wasn't expecting, um and it helps you in a really practical way as well [...] there was a desire to kind of offer something similar to people.

Having a transformational experience of a mindfulness course led to a desire to deepen one's own mediation practice, alongside a wish to pass on the potential benefit of mindfulness practice to others. Participants had a "Special relationship" with mindfulness and were thus keen to develop their teaching as an adjunct to their daily work, for personal fulfillment, and for the benefit of future MBPs participants, and beyond. Abi, for example, commented that by teaching MBSR she was "Contributing to society."

This desire to teach and pass on the benefits of mindfulness to others was also linked to an intention about how best to do this. Fiona said: "My job as a facilitator [is] to create this environment where my participants can explore and move to their own wisdom." Chris's intention centered on the importance to him of being "Absolutely authentic about what I'm doing you know and [...] I've no interest in, er, pretending or trying to be somebody that I'm not." These intentions seemed to help these participants to ground themselves in the teaching process, and their comments further point to a desire to teach with authenticity and respect for themselves, the MBSR curriculum, and the autonomy of course participants.

\section{Superordinate Theme: Professional Challenges}

Trainees were deeply concerned about how they could offer high-quality teaching with integrity. This included gaining skills, knowledge and understanding; how best to engage in reflective practice; how to get paid (or not); and how best to recruit course participants. The process of beginning to teach enabled participants to begin to understand more fully the responsibility inherent in becoming a MBPs teacher; the time, commitment, and skill this would require long-term; and a growing sense of the range of practical issues that would be need to be addressed each time they taught an MBP. This theme also highlighted issues around the professional status of MBSR teachers, as well as the challenges being faced in the professional field concerning inclusivity and accessibility to courses.

\section{Subordinate Theme: Getting to Grips with the Curriculum}

The challenge of getting to grips with the MBSR curriculum was commented on by over half the participants. Examples
Table 2 Superordinate and subordinate themes

\begin{tabular}{ll}
\hline Superordinate theme & Subordinate theme \\
\hline $\begin{array}{l}\text { Motivation to teach } \\
\text { Professional challenges }\end{array}$ & Getting to grips with the curriculum \\
& The importance of reflection \\
& "We offered it for free" \\
& Practical issues \\
& Teaching MBSR is a big commitment \\
Personal challenges & "Not good enough" \\
& Pre-course worries vs. reality \\
& "It's such rewarding work" \\
Practicing what they teach & Personal practice takes on a new significance \\
&
\end{tabular}


included making sense of the "Puzzle" of the 8-week course themes and investing considerable time and effort in order to be clear about session content. As Fiona remarked, "The things that we are actually teaching are incredibly deep and the cultivation of er all these attributes [...] could take forever for us." Stephanie said:

The 8-week course is just a start, and most people haven't really fully got it you know, even me with my background [...] doing the first 8-week I hadn't really got the depth and the richness of it [...] and [as a participant] I've done it three times (laughs).

These comments help to contextualize the task that every new teacher of MBSR faces when required to impart, through the medium of their guidance and teaching, the complexities, subtleties, and nuances of the MBSR curriculum. Fiona was able to resolve the difficulty of feeling potentially overwhelmed by this responsibility by breaking the 8-week course down session by session, and telling herself that she was "Good enough for this 8-week course" which was an important approach for her, "Otherwise I will be crushed with what I should be learning (laughs)."

\section{Subordinate Theme: The Importance of Reflection}

The majority of participants considered reflective practice to be important because it gave them a means of gaining insight into their teaching practice, which in turn helped them to grow as teachers. Kim found, for example, that reflection helped her to identify a tendency to go into "Conceptual talking, rather than truly, genuinely inquiring into the participants' experiences and let that unfold." This reflection meant that she was noticing how her habitual behavioral patterns could get in the way of allowing appropriate conditions for her participants' exploration of their experience. One participant commented that she was adapting the MBI:TAC as a reflective tool, helping her to gain a deeper understanding of the domains of competence and using this process to improve the quality of her teaching.

A few interviewees commented on the challenge of physically finding time and space to reflect after a teaching session. David remarked that he was making reflective notes on his train journey home after teaching, adding that he found reflection "Challenging [...] and whether there's any value in there being $[. .$.$] somehow more teaching around that [on the uni-$ versity course]." His comment was echoed by Jo, who felt that there was a lack of time for "Gentle reflection" on her training course "Because it's so full on when we're there."

These comments suggest that there may be uncertainties about how to reflect, and that more input on this topic on training courses might be beneficial. Stephanie thought that what she was being asked to do was "Not just reflection, it's reflexivity, looking about how we interfere with the process, gaining understanding and greater awareness of ourselves." Gaining this degree of perceptual awareness is a skill that requires deep engagement and there was a suggestion from a few participants that they were only able to pay lip service to this process, due to time pressures and a lack of knowledge and skill as to how to engage meaningfully with reflection.

\section{Subordinate Theme: We Offered it for Free}

Several interviewees remarked that they had been delivering MBSR courses for free, or charging a reduced rate, and some commented that they were not even covering their costs, despite having spent considerable sums of money on training course fees, retreats, and supervision. David remarked "Who can afford to teach? I think that's a big question for us." This comment suggests that training in mindfulness can be an expensive undertaking that is only be accessible to those with the income to afford it. Kim echoed David's remark when she stated:

I'm not doing this to make a living, so I am fortunate enough to be in that position [...] I do think it would have been extremely stressful [...] if this was something I needed to do on a commercial basis.

Several interviewees felt that the standard MBSR course was too time-consuming for course participants, or even themselves. Chris commented that "I don't know how viable 8week courses are, in terms of commitment from myself and a lot of people," and this had resulted in him offering tasters and day courses as an alternative. A few respondents were thinking about adapting MBSR (e.g., to a 4-week version) in the hope that this might make mindfulness teaching more accessible and commercially viable, but were simultaneously struggling with the dilemma this would raise, as making changes would perhaps detract from the ethos and deep learning offered by the standard 8-week MBSR curriculum. Stephanie said: "How do you [teach] in a way that yes is [...] true to MBSR and is true to the research but actually just cuts a little bit of slack?"

Her feeling seemed to be that a shorter course would attract more participants as it would be more accessible for them and therefore more inclusive, but the paradox here was that the course could not then be marketed as MBSR. This remained an unresolved dilemma for several participants.

\section{Subordinate Theme: Practical Issues}

For several interviewees, recruiting participants to participate in their MBSR courses was a "Tricky" and "Frustrating" experience. As Jo stated, "The most difficult thing that I have found, which has surprised me, is bums on seats." Jo's 
surprise suggests that she may have held presumptions about the demand for MBPs in her local area and the ease with which participants could be recruited. Stephanie described driving around for hours in her rural setting, putting up posters:

Just for getting three or four people to sign up, and it's not enough to run the course, so I have to stop. And then, when I try again, half of those have dropped off and then I get another two next time, so I've still only got four or five, you know it's still not enough.

In contrast, Mel and Chris had offered their services to voluntary organizations which recruited on their behalf, so had an easier time recruiting. The interviewees described mixed experiences around recruitment, which were more or less stressful depending on whether they were teaching privately or for established organizations. This suggests that the teaching context in which they found themselves was a contributory factor to stress for some participants, impacted on by the closed-group, linear format of the MBSR course. As Stephanie pointed out, “I didn't think about this beforehand, and I think this is where the frustration builds in, is that actually every eight weeks they go and you've got to start again."

The time, effort, energy and financial costs of recruitment (e.g., advertising, printing, web design), together with its cyclical nature, are significant aspects of MBSR delivery that appeared not to have been fully anticipated by some participants. Addressing these practical, but essential, aspects of delivering MBSR courses added a further layer of complexity and time-demand to the delivery of MBSR courses for participants, especially those for whom recruitment challenges were unexpected.

\section{Superordinate Theme: Personal Challenges}

Participants identified a number of personal challenges as they began teaching. These challenges were mainly of a practical nature - teaching an MBSR course for the first time requires a lot of preparation, time, and effort, as many materials need to be created from scratch (workbooks, audio files, orientation and advertising materials etc.). This initial time-demand lessened with subsequent courses, where preparation materials needed to be tweaked rather than created from scratch. This process of a high upfront time-demand for the first MBSR course was unexpected and stressful for some participants and challenged their organizational abilities. With time, these demands reduced, and they reported that teaching their first few MBSR courses was a rewarding experience which had gone better than anticipated. Participants took their MBP teaching very seriously and were deeply committed to offering MBPs with integrity, knowledge and compassion, and these high standards were often interlinked with anxiety about being a "good" MBPs teacher.
Subordinate Theme: Teaching MBSR Is a Big Commitment

The majority of participants commented on the considerable amount of work that was needed to prepare for their first MBSR course, and how challenging it was to commit to the time needed to do this essential work. This included writing and organizing workbooks and handouts, creating lesson plans and making audio recordings of mindfulness practices. David said that he had not quite understood what he was letting himself in for:

You don't really know what's involved um until you're doing it really [...] I don't think I'd have envisaged that it would have taken quite so much preparation even after I'd started on the [postgraduate] course, certainly beforehand $[. .$.$] I really couldn't conceive of what was$ involved.

Comments like these suggest that some participants were not prepared for the amount of work involved in delivering their first mindfulness course, especially when they wanted to do things well, or had a certain standard of delivery in mind. Preparation may have been more time consuming due to the necessarily conscientious attitude of new teachers like Chris, who "Wanted to do a good job."

Finding the time to fit in the preparation and teaching on top of work, family and study was for Mel, "A bit of a stressor [...] yeah, a big time-commitment." David noticed that "It's been quite challenging for my wife and I. We haven't spent as much time together, and so it's working out how to make more time for us and make those times special if you like." These comments hint at the wider sacrifices regarding work and family time that these new teachers made in order to commit to teaching MBPs.

There was, however, a benefit to this investment of time and effort, as the initial work of gathering materials could then be used for subsequent classes. Abi echoed the experience of several participants when she said "Obviously the second time around it's much more about fine tuning and just improving the existing material." Despite finding the preparatory phase stressful, Mel stated that it "Was an enjoyable experience as well [...] because I learned quite a lot by doing that actually." This ability to see a positive side to stressful experiences was an attitude that pervaded the commentary of the majority of participants during the interviews, indicating qualities of resilience, a willingness to use the opportunity to learn and grow, and an ability to see the whole experience from a wider perspective.

\section{Subordinate Theme: "Not Good Enough"}

Participants reported feeling anxious about their ability to teach an MBSR course, which seemed to peak before and around the first MBSR course they taught. Chris said he was nervous about teaching due to his uncertainties about 
"Knowing MBSR as well as I would like." Participants held themselves to high standards and took the responsibility of teaching seriously. Fiona, for example, spoke of her fear about not being good enough:

My knowledge is not good enough, um, I am not connected with these people, er, I am not empathetic enough, I am not sympathetic enough, I am not compassionate enough [...] so you know all these questions actually go round in my mind.

Another pitfall mentioned by several participants was being selfjudgmental about their teaching and feeling awkward and frustrated when things did not go as well as hoped, or when something was forgotten. For Kim, "It is the inquiry part where I become extremely judgmental of myself and I feel as if I'm right at the beginning." Jo articulated the commonly expressed experience of having to face up to and experience personal vulnerabilities: "I think we do judge ourselves harshly, and we set such high [standards] [... it brings us up to you know in close contact with a certain amount of suffering and our own vulnerability around performing $[\ldots]$ and responsibility."

These comments indicate the very human vulnerabilities of self-doubt, fear, worry and self-judgment that can be experienced by new teachers of MBPs, who - as neophytes - naturally have anxieties and concerns about their abilities.

\section{Subordinate Theme: Pre-Course Worries vs. Reality}

Any misgivings, worries, and self-doubt experienced by participants were somewhat quelled by the reality of the teaching experience, which went more smoothly, easily, and enjoyably than anticipated for all participants. Despite the challenges mentioned above, Chris found that teaching his first course was a "Fantastic experience" and Mel said that "It went really well, I mean much better than I was expecting." Pre-course worries about potentially "Tricky" group members, or not being able to guide practices well, were unfounded in reality.

Interestingly, not one of the participants interviewed for this study talked about their actual teaching experience in a negative way, despite being asked an open question about how they had found their teaching so far. This could be because the experience was not negative, or because the participants were mindfully skilled at negotiating challenge and difficulty and able to bring an attitude of openness to their experiences, as well as a willingness to learn from them, so any negative events were seen as part of the learning process.

\section{Superordinate Theme: Practicing What They Teach}

All participants said they found teaching MBSR intrinsically rewarding, although it was not without its challenges. They described how they used their personal practice as a support for their teaching and their well-being, to the extent that personal practice took on a new significance. In particular, the notion and practice of "embodiment" (which has been defined as a unified mind/body present-moment awareness, informed by attitudes of compassion and kindness, which infuses the ways in which we think, speak, act and relate to others [Feldman and Kuyken 2019]) during teaching helped participants meet difficult moments in class, and also acted as a reliable support throughout the process.

\section{Subordinate Theme: "It's Such Rewarding Work"}

All the participants in the study commented on how they found teaching MBPs a rewarding experience. Abi, for example, said:

I have absolutely loved it! Just [...] that sense of the group as it starts to bond, and people opening up, seeing people develop [and] begin to notice their patterns, and it feels really $[\ldots]$ a privilege to facilitate that, so I do find it a joyful thing to do.

Other interviewees echoed this remark, commenting on the joy they felt, particularly when noticing changes in their course participants. Chris noticed how participants "Looked more relaxed and more at ease," Stephanie enjoyed "Seeing them moving and growing and changing," and Kim commented how "When I see them express [...] that some big 'aha' has happened to them, that really brings me joy." Stephanie remarked on the vulnerability and courage that she observed in her course participants:

I'm always touched by um how vulnerable and courageous people need to be to do this work. It's not an easy thing to do, to lift the bonnet and to be looking at all of our processes, especially in a group situation with a bunch of strangers, so I'm always moved by $[. .$.$] what$ people will do, and $[\ldots]$ that brings me joy.

Jo summed up these experiences by stating "It's such rewarding work." These comments suggest that these interviewees experienced a real "Feel-good" factor when observing the transformation of their course participants, bringing them a sense of personal satisfaction. This sense of worthwhile work may have helped to mitigate the aforementioned difficulties of financing and organizing courses that participants had experienced.

\section{Subordinate Theme: Personal Practice Takes on a New Significance}

The majority of participants commented on an enhanced relationship to their personal mindfulness practice since starting 
teaching, and this manifested in a number of ways. David found that, "If I'm feeling nervous or apprehensive in interactions with participants," he could deliberately bring these challenges from his teaching experience into his loving-kindness meditation practice at home, which for him was particularly helpful. Chris felt that he had become "More understanding of myself than maybe I would have been originally" and attributed this to the development of his practice. Fiona, who had a long meditation practice, had found that "I sometimes touch my inner wisdom [when practicing] but not always, so I have to be patient with myself so that I can be patient [...] with participants." This comment gives a clear example of how practice can cultivate an ever-deepening relationship to the self, and how new teachers like Fiona could draw on their practice, not only as a means of personal support, but also as a means of developing the relational aspects of teaching through a shared understanding of the challenges and benefits of practice.

The majority of participants were also able to give examples of how, during teaching, they were able to experience connection to their practice through embodiment. For Jo:

My personal practice gives me trust in the process; trust, so that $[\ldots]$ embodying that I suppose could be potent for the participants, because if I have trust in the process then they are more likely to be able to trust it in the face of difficult challenges.

This "Trust in the process" could be in reference to the ongoing cultivation of embodiment that most interviewees described drawing upon when meeting difficult moments - the process of "turning towards" their struggles with the unwanted (whether a thought, feeling or body sensation). This seemed to be a very supportive way for them of managing the "Little bumps" that occurred during teaching. Jo noted that "When those moments of difficulty [...] come up, or fear might be there, or that overburdening responsibility, then having that capacity to drop into what's going on for myself is underpinned by my regular practice, my daily practice." Mel noticed a tendency to lean forward during moments of tension, and so used her awareness to pause and relax: "I was also kind of really delighted as well inside, going 'oh well look, look, you noticed in the moment!' (laughs)." Her laughter suggests that she was able to bring a light and playful quality of attention to her experience.

These comments draw attention to the significance and importance that the participants placed on their embodiment of their personal practice during the process of teaching. As such it suggested that personal practice was, to use Jo's word, the "Bedrock" for their teaching practice and an essential support when negotiating moments of challenge during teaching sessions. Participants' comments also indicated that the process of developing as an MBP teacher deepened their mindfulness practice and brought them into more intimate contact with the attitudinal foundations of mindfulness (e.g., non-judging, trust, patience). They found opportunities within the teaching challenges, such as a deepening patience (Fiona) and an increase in "turning towards" tension (Mel), because they were aiming to embody mindfulness and "practice what they teach." This suggests personal mindfulness practice and training in the delivery of MBPs may exist in a symbiotic relationship.

\section{Discussion}

This study aimed to explore the experiences of MBP trainees' teaching their first MBSR courses, the ways in which they negotiated any challenges, and what role their mindfulness practice played during this process. A deep and ongoing commitment to teaching MBPs to the best of their ability was threaded throughout their accounts, and key findings were: that trainee teachers only understood the amount of time, effort and commitment needed to deliver MBSR once they had to do this themselves; there were concerns about whether trainees could adapt MBSR; skills in how to reflect on teaching experience may be underdeveloped; and trainee teachers do indeed practice what they teach, and use their personal mindfulness practice as a deep source of personal support. The key findings will be explored in turn below.

\section{Trainee Teachers Under-estimated the Amount of Time, Effort, and Commitment Needed to Deliver MBSR}

The majority of participants commented on how challenging they had found the practicalities of preparing to teach their first MBSR courses, and how they were somewhat taken aback by the amount of time, effort, cost, and commitment this involved. The implication here was that they had not fully anticipated the workload of this stage of the process, nor the impact this might have on their daily lives and close relationships. Recent research concerned with issues related to teacher preparedness to teach has focused on the importance of teacher competency and integrity (Crane et al. 2010; Crane et al. 2012; Crane et al. 2016). While the data suggest that participants had gained (or were gaining) much of great value from their training programs, equally it appeared that more input was needed around the practicalities involved in putting their learning and experience into operation. This suggests that more emphasis on the practical realities of what trainees might be facing as first-time teachers might help with their preparation (along the lines of "forewarned is forearmed") and the inclusion of some additional content around this area in training course curricula would be welcomed by trainees. Once participants had developed their materials for teaching, this 
workload dropped considerably as they could reuse their materials for future courses.

Recruitment to MBSR courses was an ongoing challenge for those who taught privately, although those who were teaching for voluntary organizations, for example, did not have recruitment issues. The findings suggest that not having a direct source from which to recruit MBP participants can be a contributory factor to stress. Several participants also mentioned that they were unable to make enough money from teaching courses and would struggle to provide courses on a "commercial basis." This could lead to various implications for teaching MBSR in non-clinical settings, such as MBP teacher training and teaching only being available to those who can afford to do so, which could lead to inclusivity and diversity issues, such as MBP teachers as a whole being unrepresentative of general public populations. This latter issue is not unique to MBP teacher training, and is similar to inclusively and diversity issues highlighted in psychology training as a whole (e.g., Callahan et al. 2018).

\section{Concerns About the Format of MBSR}

Although fewer than half of the participants expressed concerns about the feasibility of offering an 8-week format of MBSR to the public, nevertheless the conversations around this topic took up a reasonable portion of the interviews of those that did. The findings from the study suggest that these concerns were linked to the direct experience of participants of the demands that it was felt teaching MBSR made on the teacher's time, and the demands that attending a full 8-week course made on course participants, which together made recruitment difficult and teaching onerous. It was felt that prospective participants were not enrolling on MBPs because they were time-poor, and this consequently led the study interviewees to consider changing the MBSR format to shorter, and therefore possibly more accessible, formats.

This generates a potential difficulty, as the evidence base is largely built upon standard 8-week MBPs (Dimidjian and Segal 2015; Kuyken et al. 2016), and participants were fully aware of this tension between practicalities and integrity. MBPs offer an approach to living that enable individuals to become more aware of habits of thought and functioning in order to facilitate an increased ability to take care of themselves in the context of how things really are, and as such offer individuals an invitation to develop skills in making wiser choices about how best to respond to the vagaries of everyday life (Segal et al. 2013). The MBSR course is designed to allow participants to embed complex concepts and digest what is in essence a radical change in accommodating difficulty and suffering in everyday life and, if all goes well, to begin to experience the benefits. This all takes time and is a process that, perhaps, cannot be rushed. Kabat-Zinn (2013) has commented on how participating in MBPs requires people to re-arrange their schedules and priorities, and how this can initially increase stress in the short term. Mindfulness training is therefore not a "quick fix." The fact that trainee teachers were open about this dilemma was encouraging and a testament to their knowledge of MBPs, as none had acted on this perceived pressure to offer shorter courses precisely because they did not want to "dilute" MBSR. This was an area of tension that seemed to arise from their direct experience of the difficulty of recruiting participants and finding that MBSR teaching was more time-consuming than anticipated. Participants were holding firm among perceived pressures to shorten the course and shared the concerns of some commentators that the alteration of MBP formats could risk spreading diluted, simplified versions of MBPs into the world (Commellato and Giommi 2016; Feldman and Kuyken 2019). As mindfulness teaching is an emergent profession (Crane 2016) this important issue suggests that new teachers might be vulnerable to certain pressures once out in the real world of teaching, and may well benefit from further dialog on their training courses about these sorts of professional pressures. If trainers can thus anticipate that some trainees may feel pressured to shorten courses due to time demands and difficulty recruiting during their first forays into teaching, then this pressure and ways to mitigate it can be made explicit before and during the training process. For example, these recruitment and workload issues could be brought to the fore in MBPs training, alongside reassurances that the workload associated with delivering a course will reduce as trainees gain teaching experience.

\section{Skills in How to Reflect on Teaching Experience May Be Underdeveloped}

Some participants felt that they wanted more opportunities to develop their reflective skills on their training course. Participants acknowledged the value of reflection as a process that could deepen engagement with learning and afford insight into their teaching practice, but some were uncertain how to develop their reflective skills.

The processes of reflection that were being utilized by the participants in the study included making notes after sessions, using supervision as a reflective space, or using the MBI:TAC as a framework for reflection (Crane et al. 2018). Reflection is an area that might be worthy of increased focus on MBP training courses, as the theme of self-awareness and reflection is regarded as crucial for the development of resilience and relational depth in the helping professions, as well as a means by which practitioners can better understand the significance and impact of their personal beliefs, attitudes and values in the helping space (British Association for Counselling and Psychotherapy [BACP] 2018; Krasner 2016). As one participant in the study commented, however, there was a lack of time for "Gentle reflection" on her university training course 
"Because it's so full on when we're there." There have been some recent field developments around reflective practice for MBPs which may assist with this issue; a reflective version of the MBI:TAC has been developed, called the MindfulnessBased Interventions: Teaching and Learning Companion (MBI:TLC: Griffith et al. 2020). This tool offers MBPs trainees a standard framework for reflecting on their MBP teaching practice, and thus may enable reflective practice to be brought more formally into teacher training programs.

\section{Trainee Teachers Do Practice What They Teach}

It had been anticipated that new teachers of MBPs would report a struggle with self-doubt and lack of confidence (Crane 2014; Evans et al. 2015), but this appeared not to be the experience of the participants interviewed for this study. Although participants did discuss having to negotiate their vulnerabilities, they did not seem to be overwhelmed by preteaching nerves or anxieties. Instead, the responses of the majority of participants in the study seemed to suggest that they were approaching their teaching responsibilities with a sense of equanimity and perspective that appeared to protect them from being destructively harsh and critical of themselves. Participants' comments suggested that they were instead focused on using their experiences to learn and engage deeply with the processes of teaching, including caring for their course participants by delivering a quality course, and deepening their knowledge and understanding of the curriculum content. The overall impression was that they had found their teaching experiences to be enjoyable and rewarding.

The findings of the study provide evidence that trainee teachers did indeed practice what they were teaching, and this seemed to be a crucial factor which enabled them to support themselves when navigating their personal vulnerabilities and the practical challenges that they were facing. The support of their personal practice may also explain how a number of participants found that the actual teaching was easier than expected. The majority of participants commented on how they experienced their personal mindfulness practice as an integral component of their teaching, for example by helping them feel grounded, trusting, and compassionate about their own experience, and in particular how their experience of embodiment helped them tune into, and negotiate, moments of challenge and difficulty when teaching (Crane 2009; Woods 2016). This finding is in line with previous research and pedagogical models (Griffith et al. 2019; van Aalderen et al. 2014) which emphasize the importance of a personal mindfulness practice, both as the principal means through which teachers model mindfulness in class, and in fostering a sense of equality between themselves and their course participants, characterized by their shared relationship with practice.

The foundation of a well-established mindfulness practice, in which the attitudinal qualities (Kabat-Zinn 2013) are wellembedded as a way of being, may further explain the ability with which the participants in this study were able to manage many of their challenges. Through a personal mindfulness practice of some years, they had experience in turning towards difficulty and had developed skills around managing their reactivity (Segal et al. 2013). An example of this would be the skill of "decentering" or being able to step back from challenging thoughts and emotions and perceive them as passing mental events that do not necessarily reflect reality (Crane 2009). This study therefore offers tentative evidence of the symbiotic relationship between mindfulness teaching and practice.

\section{Limitations and Future Research}

Qualitative research methods, such as thematic analysis, are generally associated with smaller sample sizes (Braun and Clarke 2013). Although the number of participants interviewed was in keeping with recommendations for a small-scale study, the data pertain to a particular context and as such cannot claim to be generalizable to wider contexts. Similarly, despite attempts to recruit from two training institutions, participants were receiving training from the same university, which meant that the study lacked in diversity of participant training experience which may have impacted the ecological validity of the study (Braun and Clarke 2013). It is also important to note that the focus and emphasis on the development of reflective skills might be different in other institutions or other training pathways. Although all the participants were in the early stages of their teaching, there were still differences in the numbers of courses they had taught (ranging from one to three), and length of time participants had a personal practice of mindfulness (range 4-10 years), so this may have led to different interpretations of experience (van Aalderen et al. 2014). That said, these differences did not appear to impact results: for example, similar responses about integrating practice into their teaching could be found among trainees with differing lengths of practice, consistent with research that found that length of the MBP teacher's practice did not influence participant outcomes (Ruijgrok-Lupton et al. 2018).

A challenging consideration for the first author was the need to hold her awareness of her insider position, that is, knowing that she had a shared identity with participants due to having studied on the same training course at the same institution as the participants (Braun and Clarke 2013). An important factor that helped the first author develop a neutral stance was her own teaching context, which was different from the participants (i.e., teaching MBCT in an NHS setting). Being unfamiliar with the challenge of delivering MBSR in general public settings meant that she was able to be make fewer assumptions about similarities of experience and bring genuine curiosity and impartiality to her investigation into the early teaching experiences of the participants in this study.

The first author was further aware that her prior relationship with four of the participants as a fellow student may have influenced the interview process. To protect against potential 
bias, an effort was made to be consistent and impartial during interviews. This was established during the interviews themselves by setting up a time boundary of up to $1 \mathrm{~h}$ for each interview and also agreeing with all interviewees that the interview schedule would provide a frame of reference in order to give structure and consistency to, and across, the interviews. Setting boundaries helped to maintain the focus for the interview and also helped to avoid lapsing into more informal conversation. Additionally, for data analysis, the first author kept a reflexive diary which helped navigate the dual role of researcher and acquaintance of four of the participants, acknowledging that this subjectivity is an unavoidable part of the research encounter which needed exploration. This approach seemed to create appropriate conditions for approaching the interviews and the data analysis, while keeping the inductive approach at the fore.

Exploring the experiences of new teachers of MBPs appears to be a relatively new area for research and one that could benefit from further investigation. Future research could profit from investigating the early teaching experiences of teachers from a wider range of teacher training institutions and teacher training pathways in order to extend the focus of the research base and add further insight into the experiences of these teachers of MBPs. Future research that explores and compares the subjective experiences of both novice and established teachers of MBPs could also serve as a complement to existing research into teacher competency and integrity, perhaps adding an additional dimension to the existing literature base on teacher training and teacher experience and further enhance our knowledge and understanding about the wider role of the MBP teacher. It may also be useful to investigate further around the impact of new and more experienced teachers on their participants, building on the research by Ruijgrok-Lupton et al. (2018).

Future research could also help to offer insights into the similarities and differences between the teaching contexts of those offering MBPs independently, those working for voluntary organizations and those who work for large, publicly funded organizations like the NHS. This study was conducted in the UK and it may be that MBPs training approaches may vary across different countries and cultural contexts, although to our knowledge there is no clear divide between MBPs teacher training in the UK and elsewhere in the world, as teacher training programs draw upon similar pedagogical sources. Broadening the research area to different countries and contexts may generate a greater understanding of the challenges of working in each of these contexts, and could therefore serve to better anticipate some of the pressures that new teachers of MBPs face, especially in the initial phase of their teaching careers.

Acknowledgments Thanks and appreciation are owed to the study participants who so kindly agreed to be interviewed, and for the generous manner in which they shared so much about their experiences as new teachers.
Author Contributions AB: designed and conducted the study and analysis, and wrote the first version of the manuscript: $\mathrm{KN}$ : was supervisor of the first author in the conduct of the research and analysis: GMG: revised and edited the original manuscript for publication. All authors edited and approved the submitted article

\section{Compliance with Ethical Standards}

Conflict of Interest $\mathrm{AB}$ declares that they have no conflict of interest. $\mathrm{KN}$ declares that they have no conflict of interest. GMG is director of a postgraduate program which trains mindfulness-based program teachers.

Ethical Approval All procedures performed in studies involving human participants were in accordance with the ethical standards of the institutional and/or national research committee and with the 1964 Helsinki declaration and its later amendments or comparable ethical standards.

Informed Consent Informed consent was obtained from all individual participants included in the study.

Open Access This article is licensed under a Creative Commons Attribution 4.0 International License, which permits use, sharing, adaptation, distribution and reproduction in any medium or format, as long as you give appropriate credit to the original author(s) and the source, provide a link to the Creative Commons licence, and indicate if changes were made. The images or other third party material in this article are included in the article's Creative Commons licence, unless indicated otherwise in a credit line to the material. If material is not included in the article's Creative Commons licence and your intended use is not permitted by statutory regulation or exceeds the permitted use, you will need to obtain permission directly from the copyright holder. To view a copy of this licence, visit http://creativecommons.org/licenses/by/4.0/.

\section{References}

Allen, M., Bromley, A., Kuyken, W., \& Sonnenberg, S. J. (2009). Participants' experiences of mindfulness-based cognitive therapy: "It changed me in just about every way possible". Behavioural and Cognitive Psychotherapy, 37(4), 413-430.

BAMBA (2019). British Association for Mindfulness-Based Approaches. https://bamba.org.uk/.

Bartley, T. (2012). Mindfulness-based cognitive therapy for cancer. Wiley-Blackwell.

Brandsma, R. (2017). The mindfulness-teaching guide: Essential skills and competencies for teaching mindfulness-based interventions. New Harbinger.

Braun, V., \& Clarke, V. (2006). Using thematic analysis in psychology. Qualitative Research in Psychology, 3(2), 77-101.

Braun, V., \& Clarke, V. (2013). Successful qualitative research: A practical guide for beginners. Sage.

British Association for Counselling and Psychotherapy. (2018). The ethical framework for the counselling professions. https://bacp.co.uk.

Callahan, J. L., Smotherman, J. M., Dziurzynski, K. E., Love, P. K., Kilmer, E. D., Niemann, Y. F., \& Ruggero, C. J. (2018). Diversity in the professional psychology training-to-workforce pipeline: Results from doctoral psychology student population data. Training and Education in Professional Psychology, 12(4), 273285. https://doi.org/10.1037/tep0000203. 
Chaplain, R. P. (2008). Stress and psychological distress among trainee secondary teachers in England. Educational Psychology, 28(2), 195-209. https://doi.org/10.1080/01443410701491858.

Chiesa, A., \& Seretti, A. (2009). Mindfulness-based stress reduction for stress management in healthy people: A review and meta-analysis. The Journal of Alternative and Complementary Medicine, 15(5), 593-600. https://doi.org/10.1089/acm.2008.0495.

Commellato, A., \& Giommi, F. (2016). Teaching in Italy. In D. McCown, D. Reibel, \& M. S. Micozzi (Eds.), Resources for teaching mindfulness: An international handbook (pp. 161-176). Springer.

Crane, R. S. (2009). Mindfulness-based cognitive therapy. Routledge.

Crane, R. S. (2014). Some reflections on being good, on not being good and on just being. Mindfulness, 6, 5, 1226-1231. https://doi.org/10. 1007/s12671-014-0350-y.

Crane, R. S. (2016). Implementing mindfulness in the mainstream: Making the path by walking it. Mindfulness, 8(3), 585-594. https://doi.org/10.1007/s12671-016-0632-7.

Crane, R. S., \& Reid, B. (2016). Training mindfulness teachers: Principles, practices and challenges. In D. McCown, D. Reibel, \& M. S. Micozzi (Eds.), Resources for teaching mindfulness: An international handbook. New York: Springer

Crane, R. S., Kuyken, W., Hastings, R., Rothwell, N., \& Williams, J. M. G. (2010). Training teachers to deliver mindfulness-based interventions; learning from the UK experience. Mindfulness, 1, 74-86. https://doi.org/10.1007/s12671-010-0010-9.

Crane, R. S., Kuyken, W., Williams, J. M. G., Hastings, R. P., Cooper, L., \& Fennell, M. J. V. (2012). Competence in teaching mindfulnessbased courses: Concepts, development and assessment. Mindfulness, 3(1), 76-84. https://doi.org/10.1007/s12671-011-0073-2.

Crane, R. S., Brewer, J., Feldman, C., Kabat-Zinn, J., Santorelli, S., Williams, J. M. G., \& Kuyken, W. (2016). What defines mindfulness-based programs? The warp and the weft. Psychological Medicine, 47, 990-999. https://doi.org/10.1017/S0033291716003317.

Crane, R. S., Soulsby, J. G., Kuyken, W., Williams, J. M. G., \& Eames, C. (2018). The universities of Bangor, Exeter \& Oxford manual of the mindfulness-based interventions teaching assessment criteria (MBITAC) (version 2018). Mindfulness Teaching Skills. http://mbitac.bangor. ac.uk/documents/MBITACmanualsummaryandaddendums0517.pdf

Dimidjian, S., \& Segal, Z. V. (2015). Prospects for a clinical science of mindfulness-based intervention. American Psychologist, 70(7), 593-620. https://doi.org/10.1037/a0039589.

Evans, A., Crane, R., Cooper, L., Mardula, J., Wilks, J., Surawy, C., Kenny, M., \& Kuyken, W. (2015). A framework for supervision for mindfulness-based teachers: A space for embodied mutual inquiry. Mindfulness, 6, 572-581. https://doi.org/10.1007/s12671-014-0292-4.

Feldman, C., \& Kuyken, W. (2019). Mindfulness: Ancient wisdom meets modern psychology. The Guilford Press.

Girardini, D. (2019). The formative role of retreats in my development as a mindfulness teacher: An autoethnography enquiry [MSc thesis, Bangor University]. https://www.bangor.ac.uk/mindfulness/ mastersresearch.php.en

Griffith, G. M., Bartley, T., \& Crane, R. S. (2019). The inside out group model: Teaching groups in mindfulness-based programs. Mindfulness, 10, 1315-1327. https://doi.org/10.1007/s12671-019-1093-6.

Griffith, G.M., Crane, R.S., Karunavira., \& Koerbel, L. (2020). The mindfulness-based intervention: Teaching and learning companion (MBI:TLC). In R.S Crane, Karunavira., \& G. M. Griffith. (Eds.), Essential resources for mindfulness teachers. Routledge. (in press)

Hanley, M. (2002). Stress. In N. Brace \& H. Westcott (Eds.), Applying psychology. The Open University.

Joffe, H. (2012). Thematic analysis. In D. Harper \& A. R. Thompson (Eds.), Qualitative research methods in mental health and psychotherapy. Wiley.

Kabat-Zinn, J. (2011). Some reflections on the origins of MBSR, skillful means, and the trouble with maps. Contemporary Buddhism, 12, 281-306. https://doi.org/10.1080/14639947.2011.564844.
Kabat-Zinn, J. (2013). Full catastrophe living: How to cope with stress, pain and illness using mindfulness meditation (2nd ed.) Piatkus.

Khoury, B., Leconte, T., Fortini, G., Masse, M., Therien, P., Bouchard, V., Chapleau, M., Pacquin, K., \& Hofman, S. G. (2013). Mindfulnessbased therapy: A comprehensive meta-analysis. Clinical Psychology Review, 33(6), 763-771. https://doi.org/10.1016/j.cpr.2013.05.005.

Krasner, M. S. (2016). Teaching health care professionals. In D. McCown, D. Reibel, \& M. S. Micozzi (Eds.), Resources for teaching mindfulness: An international handbook. Springer.

Kumary, A., \& Baker, M. (2008). Stresses reported by UK trainee counselling psychologists. Counselling Psychologist Quarterly, 21(1), 19-28. https://doi.org/10.1080/09515070801895626.

Kuyken, W., Warren, F. C., Taylor, R. S., Whalley, B., Crane, C., Bondolfi, G., Hayes, R., Huijbers, M., Ma, H., Schweizer, S., Segal, Z., Speckens, A., Teasdale, J. D., Van Heeringen, K., Williams, M., Byford, S., Byng, R., \& Dalgleish, T. (2016). Efficacy of mindfulness-based cognitive therapy in prevention of depressive relapse: An individual patient data meta-analysis from randomized trials. Journal of the American Medical Association: Psychiatry., 73(6), 565-574. https://doi.org/10.1001/ jamapsychiatry.2016.0076.

Levitt, H.M., Bamberg, M., Creswell, J.W., Frost, D.M., Josselson, R., \& Suárez-Orozco, C. (2018). Reporting standards for qualitative research in psychology. The APA Publications and Communications Board Task Force Report.

McCown, D., Reibel, D., \& Micozzi, M. S. (2011). Teaching mindfulness: A practical guide for clinicians and educators. Springer.

Mindfulness All-Party Parliamentary Group. (2015). Mindful nation UK. https://www.themindfulnessinitiative.org/Handlers/Download. ashx?IDMF=1af56392-4cf1-4550-bdd1-72e809fa627a.

Parsons, C. E., Crane, C., Parsons, L. J., Fjorback, L. O., \& Kuyken, W. (2017). Home practice in mindfulness-based cognitive therapy and mindfulness-based stress reduction: A systematic review and metaanalysis of participants' mindfulness practice and its association with outcomes. Behavior Research and Therapy, 95, 29-41. https://doi.org/10.1016/j.brat.2017.05.004.

Rimes, K. A., \& Wingrove, J. (2011). Pilot study of mindfulness-based cognitive therapy for trainee clinical psychologists. Behavioral and Cognitive Psychotherapy, 39(2), 235-241. https://doi.org/10.1017/ 51352465810000731.

Ruijgrok-Lupton, P. E., Crane, R. S., \& Dorjee, D. (2018). Impact of mindfulness-based teacher training on MBSR participant wellbeing outcomes and course satisfaction. Mindfulness, 9, 117-128. https://doi.org/10.1007/s12671-017-0750-x.

Segal, Z. V., Williams, J. M. G., \& Teasdale, J. D. (2013). Mindfulnessbased cognitive therapy for depression (2nd ed.). The Guilford Press.

Speeth, K. R. (1982). On psychotherapeutic attention. The Journal of Transpersonal Psychology, 14(2), 141-160.

Truell, R. (2001). The stresses of learning counselling: Six recent graduates comment on their personal experience of learning counselling and what can be done to reduce associated harm. Counselling Psychology Quarterly, 14(1), 67-89. https://doi.org/10.1080/09515070110059133.

van Aalderen, J. R., Breukers, W. J., Reuzel, R. P. B., \& Speckens, A. E. M. (2014). The role of the teacher in mindfulness-based approaches: A qualitative study. Mindfulness, 5, 170-178. https://doi.org/10. 1007/s12671-012-0162-x.

Willig, C. (2013). Introducing qualitative research in psychology (3rd ed.). McGraw-Hill Education.

Woods, S. L. (2016). Teaching individuals with anxiety and depression. In D. McCown, D. Reibel, \& M. S. Micozzi (Eds.), Resources for teaching mindfulness: An international handbook. Springer.

Yardley, L. (2000). Dilemmas in qualitative health research. Psychology and Health, 15(2), 215-228. https://doi.org/10.1080/08870440008400302.

Publisher's Note Springer Nature remains neutral with regard to jurisdictional claims in published maps and institutional affiliations. 